Article

\title{
Implant Coating Manufactured by Micro-Arc Oxidation and Dip Coating in Resorbable Polylactide for Antimicrobial Applications in Orthopedics
}

\author{
Xiao-Yan Cao ${ }^{1}$, Na Tian ${ }^{2}$, Xiang Dong ${ }^{2}$ and Cheng-Kung Cheng ${ }^{1,3, *(1)}$ \\ 1 School of Biological Science and Medical Engineering, Beihang University, Beijing 100083, China; \\ caoxiaoyan@buaa.edu.cn \\ 2 Beijing Engineering Laboratory of Functional Medical Materials and Devices, Beijing Nation Technology \\ Group Co. LTD, Beijing 100082, China; tianna@naton.cn (N.T.); dongxiang@naton.cn (X.D.) \\ 3 Beijing Advanced Innovation Center for Biomedical Engineering, Beihang University, Beijing 100083, China \\ * Correspondence: ckcheng@buaa.edu.cn; Tel.: +86-010-8233-9291
}

Received: 26 March 2019; Accepted: 24 April 2019; Published: 26 April 2019

check for updates

\begin{abstract}
Prophylaxis and the treatment of implant-related infections has become a key focus area for research into improving the outcome of orthopedic implants. Functional resorbable coatings have been developed to provide an antimicrobial surface on the implant and reduce the risk of infection. However, resorbable coatings developed to date still suffer from low adhesive strength and an inadequate release rate of antibiotics. This study presents a novel double-coating of micro-arc oxidation and resorbable polylactide copolymer on a Ti-6Al-4V implant with the aim of reducing the risk of infection post-implantation. The adhesive strength, rate of coating degradation, and antibiotic release rate were investigated. A key finding was that the micro-arc oxidation coating with the addition of antibiotics increased the adhesive strength of the poly-L-lactide-co- $\varepsilon$-caprolactone (PLC) coatings. The adhesive strength was influenced by the concentration of the PLC solution, the surface structure of the titanium substrate, and the composition of the coatings. The antibiotics blended into the PLC coating had a release cycle of approximately 10 days, which would be long enough to reduce the risk of developing an infection after implantation. The double coatings presented in this study have an excellent potential for reducing the incidence and severity of implants-related early infections.
\end{abstract}

Keywords: micro-arc oxidation coating; resorbable polylactide coating; adhesive strength; degradation rate; antibiotic release; orthopedic implants

\section{Introduction}

Complex fractures to bones are commonly treated with titanium alloy implants, such as bone plates, screws, pins or wires, and intramedullary nails [1]. While such internal and external fixation devices can rapidly stabilize the fracture, subsequent infection of the site is the most common post-surgical complication with orthopedic implants [2-4]. There are about two million nosocomial infections in the United States each year, about $30 \%-50 \%$ of which are related to implants [2,5-7]. The main cause of infection is bacteria adhering to the surface of the implant [3,8], which then gradually multiplies to form a biofilm. The internal bacteria will be protected by this biofilm, being free from phagocytosis and antibiotics, making it clinically difficult to treat $[6,9]$. Thus, prophylaxis and the treatment of implant-related infections has become a focal point for preventive medicine $[1,2,7,10,11]$.

Functional coatings applied to titanium, magnesium, and aluminum alloys have been used extensively in implants because of their antimicrobial properties, predictable degradation behavior and biocompatibility, all of which reduce the risk of post-operative infections $[1,3,8,12]$. The use of plasma 
electrolytic oxidation (PEO), also termed micro-arc oxidation (MAO), allows for coatings to have a carefully controlled composition, microstructure, porosity, and surface roughness for improved surface bioactivity [13] and corrosion resistance [12,14]. Coatings developed through MAO and embedded with inorganic antibacterial metal elements (e.g., silver, copper, and zinc) have been reported to reduce the incidence of implant-related infections, but the bioactivity and toxicity of these coatings is controversial $[1,13,15,16]$. Polylactide is polymeric material that is commonly used in orthopedics for osteosynthesis due to its biodegradability and biocompatibility [9,17]. Peltonen et al. [9] demonstrated significantly greater bacterial adhesion to the surface of titanium implants than polylactide implants. Vester et al. reported that gentamycin in poly-D,L-lactide (PDLLA) coatings on titanium implants, which is used for local prophylaxis of implant-related osteomyelitis, was released with an initial burst of $60 \%$ of the gentamycin content into phosphate buffer sailine within $1 \mathrm{~min}$ [17]. However, this rapid release rate would not sufficiently tackle early infections, which typically onset after approximately 2 weeks [2]. The release rate of antibiotics can be tailored to match the degradation rate of the polylactide matrix by altering the copolymerized monomers, molecular weight, and crystallinity [18]. Although resorbable materials embedded with antibiotics have been investigated as coatings on the surface of implants [19], the additional layer often presents complications such as substantially increasing the thickness of the device, providing a smooth coating leading to implant instability, and peeling off of the coating from the device [20].

This study presents a new double implant coating composed of micro-arc oxidation (MAO) and resorbable polylactide embedded with antibiotics with the aim of reducing the incidence of infection after implantation. To evaluate the antibacterial potential of this double coating, the investigation considered the effect of different concentrations of resorbable PLC in organic solvent on the thickness of the coating and morphology of the Ti-6Al-4V blocks with MAO coating, the adhesion strength between the resorbable polylactide coating and MAO coating, and the degradation and drug release properties of the PLC coating.

\section{Materials and Methods}

Figure 1 shows three separate flowcharts of testing performed in this study. (i) The first flowchart details the study of the thickness and morphology of coatings with different concentrations of PLC solution; refer to Sections 2.1 and 2.2. The PLC coating was applied to Ti-6Al-4V blocks $(n=10)$ by dip coating [21] in concentrations of $1,3,5,8,12 \mathrm{wt} \%$, respectively. (ii) The second flowchart is the investigation of adhesive strength of four groups of coatings, as detailed in Section 2.3. The four coatings were (1) PLC coating (group 1, $n=10$ ), (2) PLC coating with antibiotics (group 2, $n=10$ ), (3) double coating of MAO and PLC (group 3, $n=10$ ), and (4) double coating of MAO and PLC with antibiotics (group $4, n=10$ ). The coatings were applied to Ti-6Al-4V test specimens according to the standard ISO 4624 [22] ( $n=40$, in total). (iii) The third flowchart details two independent studies, which are the degradation properties of PLC coatings $(n=33)$ and the cumulative drug release of antibiotics from double coatings $(n=3)$, as discussed in Section 2.4. The double coating with antibiotics was applied to Ti-6Al-4V blocks ( $n=36$, in total). The study was performed in a phosphate buffer saline. 


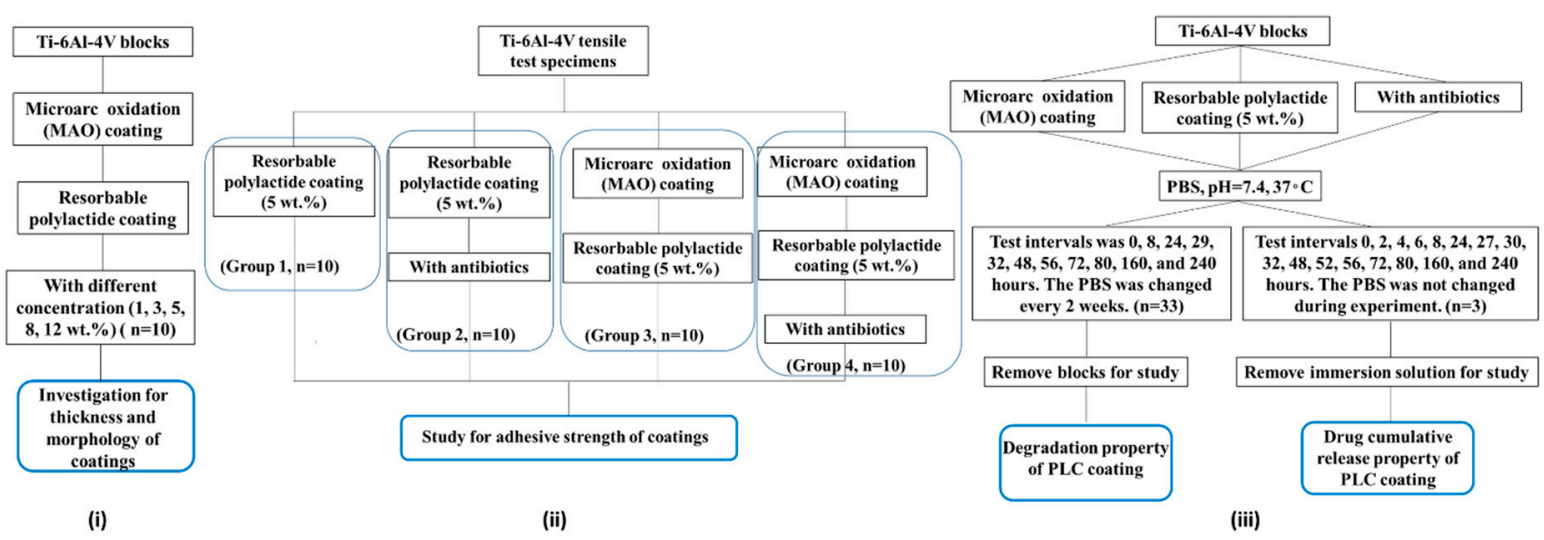

Figure 1. Diagrams of the experimental design.

\subsection{Preparation of Coatings on Ti-6Al-4V Blocks}

Ti-6Al-4V blocks of dimensions $1 \mathrm{~cm} \times 1 \mathrm{~cm} \times 0.45 \mathrm{~cm}$ were supplied by Naton Group, Beijing, China (Figure 2). The MAO coating was produced using the method reported by Cheng et al. [23], by which the Ti-6Al-4V blocks and tensile test specimens were separately placed in an electrolyte created by the dissolution of $\mathrm{Ca}\left(\mathrm{CH}_{3} \mathrm{COO}\right)_{2} \cdot \mathrm{H}_{2} \mathrm{O}(0.05 \mathrm{~mol} / \mathrm{L}), \mathrm{Na}_{2} \mathrm{SiO}_{3}(0.116 \mathrm{~mol} / \mathrm{L})$, ethylenediaminetetraacetic acid disodium $(0.045 \mathrm{~mol} / \mathrm{L})$ and $\mathrm{NaOH}(0.5 \mathrm{~mol} / \mathrm{L})$ in deionized water (Sinopharm group, Beijing, China). The resorbable poly-L-lactide-co- $\varepsilon$-caprolactone (PLC, Corbion Purac, Amsterdam, the Netherlands) coating, with and without antibiotics, was created using a dip coating method [21]. First the PLC was dissolved in acetonitrile (Sinopharm group, Beijing, China) to prepare solutions with PLC concentrations of $1,3,5,8$, and $12 \mathrm{wt} \%$. The Ti-6Al-4V blocks with micro-arc oxidation (MAO) coating were ultrasonically washed in acetone, ultrapure water, and $75 \%$ ethanol, then dried in a fuming hood. The blocks were then dipped into the above formulated solutions three times, taken out at room temperature for $48 \mathrm{~h}$ and then vacuum dried for $48 \mathrm{~h}$ to obtain double-coated Ti-6Al-4V blocks. Using different concentrations of PLC solution allowed the thickness of the PLC coating and morphology of the Ti-6Al-4V blocks with MAO coating to be studied.

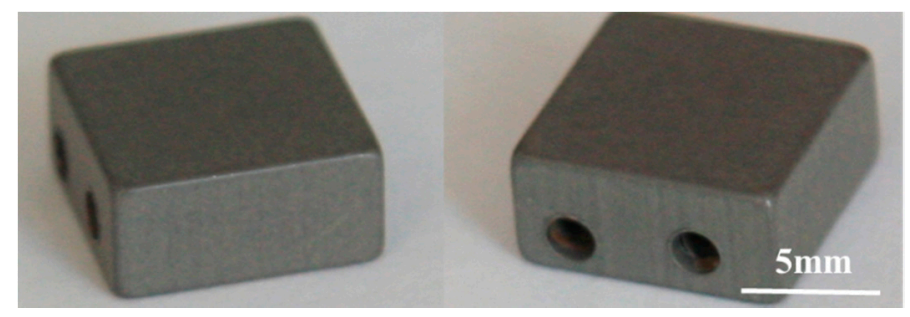

Figure 2. The Ti-6Al-4V block with MAO coating.

Similarly, resorbable PLC coatings blended with the antibiotics rifampicin and minocycline hydrochloride (Sigma Co., St. Louis, MO, USA) were also developed. A weight ratio of 1:1 rifampicin and minocycline hydrochloride was dissolved in methanol (Sinopharm group, Beijing, China) to obtain solution 1. PLC was dissolved in acetonitrile at a concentration of $5 \mathrm{wt} \%$ to obtain solution 2 . The volume of methanol in solution 1 was one-third the volume of acetonitrile in solution 2 . The antibiotic solution 1 was then slowly stirred into the PLC solution 2 . The dosage of antibiotics was $12.5 \mathrm{mg} / \mathrm{mL}$ in the final mixture. The Ti-6Al-4V blocks were then ultrasonically washed in acetone, ultrapure water, and $75 \%$ ethanol, before being dried in a fuming hood. The blocks were then dipped into the formulated solution three times, taken out at room temperature for $48 \mathrm{~h}$ and vacuum dried for $48 \mathrm{~h}$ to obtain double-coated Ti6-Ai4-V blocks with antibiotics. 


\subsection{Morphology and Thickness of Double Coatings}

The surface morphology of the MAO coating before and after dip coating in the resorbable PLC solution with concentrations of $1,3,5,8$, and $12 \mathrm{wt} \%$ was investigated by scanning electron microscopy (SEM, Hitachi, Tokyo, Japan, S4800). The surface was coated by gold sputtering.

Similarly, the cross-section morphology and thickness of the resorbable PLC coating was imaged using SEM and measured $(n=3)$ using the software Image J 1.40g, Bethesda, MD, USA. A cross section of the PLC coating was prepared using a fine-tipped tweezers and coated by gold sputtering to improve the electro conductivity. All results are given as a mean and standard deviation.

\subsection{Tensile Test for Adhesion Strength between MAO Coating and Resorbable PLC Coating}

Tensile test specimens of Ti-6Al-4V $(n=40)$ were produced according to the dimensions specified in ISO 4624, with a diameter of $20 \mathrm{~mm}$ and height of $15 \mathrm{~mm}$ (Figure 3A). Ten specimens were assigned to each of the four groups: PLC coated, PLC coated with antibiotics, PLC and MAO double-coating, and PLC and MAO double-coating with antibiotics. The resorbable PLC coatings were created at a concentration of $5 \mathrm{wt} \%$. Each group had five pairs of test specimens, with each pair consisting of one specimen coated according to the assigned group and the other acted as a control and was coated with E7 high temperature structural adhesive (HUA YI resins, Shanghai, China). The adhesive was used to bond the pairs together, which were secured in the centering fixture to ensure alignment (Figure 3B,C), and then cured in an oven at $100^{\circ} \mathrm{C}$ for $3 \mathrm{~h}$.
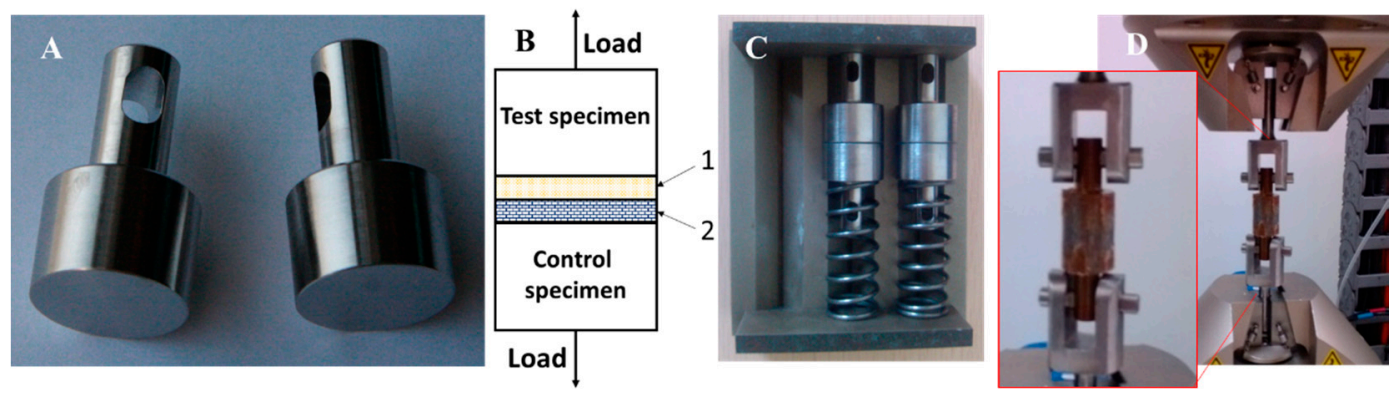

Figure 3. (A) The uncoated tensile test specimens; (B) A schematic diagram of paired blocks for tensile testing, where 1 shows the group coating on the test specimen and 2 shows the E7 high temperature structural adhesive coating on the control test specimen; (C) The centering fixture; (D) The tensile test setup (note that the addition of antibiotics gave the specimens a tarnished appearance).

The adhesion strength of each pair from the four groups was measured through tensile testing with an Instron E3000 (Instron Co., Boston, MA, USA) in accordance with ISO 4624. The load cell capacity was $3 \mathrm{kN}$. The test setup is shown in Figure 3D, where the specimens were loaded at a constant speed of $2.5 \mathrm{~mm} / \mathrm{min}$ until failure. Given the different coatings applied to the test samples (Figure 3B), there are a number of interfaces where failure could occur (Table 1). Loading was applied using displacement control. The maximum tensile load $(F$, in $\mathrm{N})$ was identified from the recorded load-displacement curve and the maximum adhesion strength ( $\sigma$, in $\mathrm{MPa}$ ) was calculated using Equation (1). All results are given as a mean and standard deviation. A $p$-value of less than $0.05(p<0.05)$ was defined as statistically significant. A two-tailed $\mathrm{t}$-test was conducted to compare the test results at defined points.

$$
\sigma(\mathrm{MPa})=F / A
$$

where, $A\left(\mathrm{~mm}^{2}\right)$ is the surface area of the test samples. 
Table 1. The interfaces in each group for tensile test.

\begin{tabular}{ccccc}
\hline \multirow{2}{*}{$\begin{array}{c}\text { Group } \\
\text { Number }\end{array}$} & Coatings & \multicolumn{2}{c}{ Interfaces between the Paired Specimens in Each Group (Figure 3B) } \\
\cline { 2 - 4 } & & Test Specimen & Between Specimens & Control Specimen \\
\hline 1 & Only PLC coating & Ti-PLC & PLC-E7 & E7-Ti \\
2 & Only PLC coating & Ti-PLC with & PLC-E7 with & E7 with antibiotics-Ti \\
3 & with antibiotics & antibiotics & antibiotics & E7-MAO-Ti \\
4 & Double coating & Ti-MAO-PLC & PLC-E7 & E7 with antibiotics \\
& Double coating & Ti-MAO-PLC with & PLC-E7 with & -MAO-Ti \\
\hline
\end{tabular}

\subsection{Degradation Rate and Antibiotic Delivery Rate from Resorbable PLC Coating}

Double-coated Ti-6Al-4V blocks with antibiotics $(n=36)$ were first immersed in a $20 \mathrm{~mL}$ Sörensen buffer solution ( $\mathrm{pH} 7.4 \pm 0.2)$ at $37 \pm 1{ }^{\circ} \mathrm{C}$ in a sealed glass vial. The buffer solution consisted of potassium dihydrogenphosphate $\left(\mathrm{KH}_{2} \mathrm{PO}_{4}, 0.0121 \mathrm{~mol} / \mathrm{L}\right)$ and disodium hydrogenphosphate $\left(\mathrm{Na}_{2} \mathrm{HPO}_{4}, 0.0545 \mathrm{~mol} / \mathrm{L}\right)$ in ultrapure water with a resistivity of $18.2 \mathrm{M} \Omega \cdot \mathrm{cm}$. The $\mathrm{pH}$ and temperature of the solution were measured in at least two different vials chosen randomly at each test time point.

Thirty-three Ti-6Al-4V blocks were required to examine the degradation of the PLC coating. The test intervals were $0,8,24,29,32,48,56,72,80,160$, and $240 \mathrm{~h}$. At each time point, three Ti-6Al-4V blocks were examined for mass loss and surface morphology. The PBS was changed every 2 weeks.

The mass of Ti-6Al-4V with MAO coating $(n=33)$ was measured as $w_{t 0}$ (in $\mathrm{mg}$ ), and the mass of Ti-6AL-4V with double-coating containing antibiotics was measured as $w_{t 1}$ (in $\mathrm{mg}$ ). At each time point, three Ti6-Ai4-V blocks were removed from the PBS, cleaned three times with deionized water, dried in oven for $24 \mathrm{~h}$ and then measured as $w_{t}$ (in $\mathrm{mg}$ ). The mass loss was calculated by Equation (2). All the results are given as a mean and standard deviation.

$$
\text { Mass loss }(\%)=100\left(w_{t}-w_{t 0}\right) /\left(w_{t 1}-w_{t 0}\right)
$$

The surface morphology of the double-coating with antibiotics was characterized by SEM at each time point. The surface was coated by gold sputtering prior to imaging.

Three new Ti-6Al-4V blocks were used to examine the rate of release of antibiotics from the PLC coating. The test intervals were $0,2,4,6,8,24,27,30,32,48,52,56,72,80,160$, and $240 \mathrm{~h}$. At each time point, $2 \mathrm{~mL}$ of the immersion solution was removed from each container and replaced with $2 \mathrm{~mL}$ of fresh PBS. The removed immersion solution was diluted four times by PBS for further analysis. The absorbance of each diluted solution was measured by ultraviolet-visible spectrophotometer (UV 2600, Shimadzu, Kyoto, Japan). The cumulative release concentration of antibiotics at each time point was calculated using the fitted equation of standard curves for antibiotics.

Rifampicin $(0.12722 \mathrm{~g})$ was first dissolved in PBS in a $250 \mathrm{~mL}$ volumetric flask to obtain a solution of $508.88 \mu \mathrm{g} / \mathrm{mL}$. Then the solution was diluted to concentrations of $25.44,22.39,20.36,18.32,15.27$, and $10.18 \mu \mathrm{g} / \mathrm{mL}$. The absorbance of each diluted solution was measured by UV at the maximum absorbed wavelength of $263 \mathrm{~nm}$. The concentration of rifampicin solution was then plotted against the absorbance, which was linearly fitted using the software Origin 8.0 (OriginLab, Northampton, MA, USA).

Similarly, minocycline hydrochloride $(0.04963 \mathrm{mg})$ was dissolved in PBS in a $250 \mathrm{~mL}$ volumetric flask to obtain a solution of $496.30 \mu \mathrm{g} / \mathrm{mL}$. Then the solution was diluted to concentrations of 29.78, $24.82,21.84,19.85,17.87$, and $14.89 \mu \mathrm{g} / \mathrm{mL}$. The absorbance of each diluted solution was measured at the maximum absorbed wavelength of $280 \mathrm{~nm}$. The concentration of minocycline hydrochloride was plotted against the absorbance, which was linearly fitted using Origin 8.0. 


\section{Results}

\subsection{Morphology and Thickness Characterization of Double Coatings on Ti6-Ai4-V Blocks}

Before dip coating in PLC solution, the MAO surface was observed to have a highly porous structure (Figure 4A). However, the apparent porosity of the surface decreased with increasing concentrations of the PLC solution (Figure 4B-F). Figure 4C appears to be more porous than Figure 4B due to uneven dip coating. In contrast, the resorbable PLC coating was dense and did not display any obvious pores on the surface. The interface between the PLC coating and MAO was observed to contain a number of protrusions (Figure $4 \mathrm{H}-\mathrm{J}$, white arrows). The thickness of the PLC coating increased with increasing concentrations of PLC solution (Figure 4G-L). At a concentration of 5 wt $\%$, the porous structure of MAO coating was just filled by the PLC, leaving only a few large pores partially filled by the PLC to ensure a rough surface of implant. The thickness of the PLC coating was $5.4 \pm 0.2 \mu \mathrm{m}$.
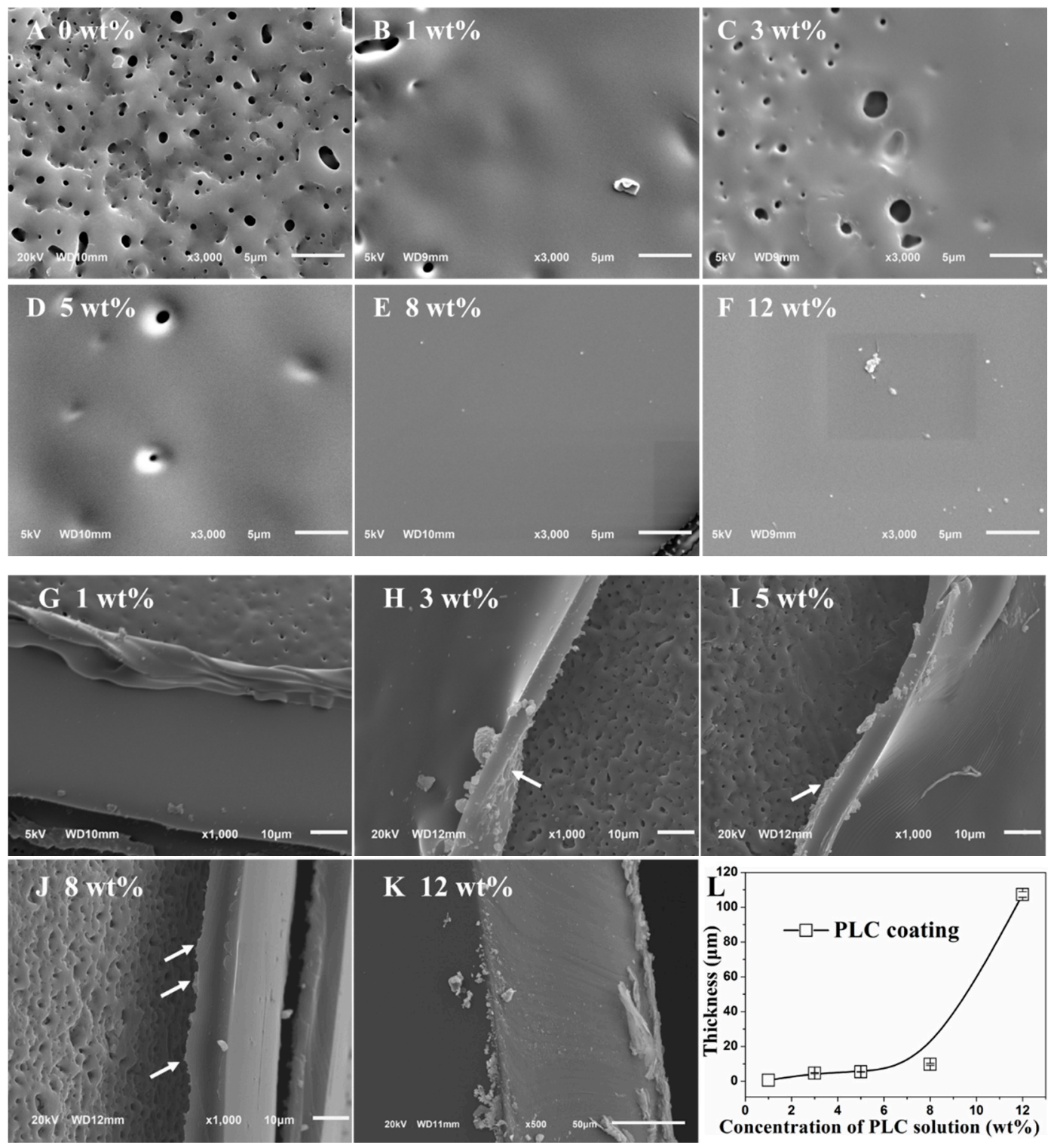

Figure 4. (A) Surface morphology of MAO coating; (B-F) Surface morphology and (G-L) cross-section morphology and thickness of PLC resorbable coating at solution concentrations of $1,3,5,8$, and 12 wt \%. 


\subsection{Adhesion Strength between MAO Coating and Resorbable PLC Coating}

For each group, the bonded pairs mainly separated at the interface between the PLC coating and E7 adhesive film (Figure 5). Table 2 contains a summary of the observed location of failure and which interfaces demonstrated strong bonding where failure was unlikely to occur. The pairs primarily failed at the PLC-E7 interface, indicating stronger adhesion between PLC-MAO and PLC-Ti. The control specimen in each pair also displayed separation at the E7-Ti or E7-MAO interface, and produced an almost symmetrical fracture pattern (white arrows in Figure 5). The fracture surface observed at the E7-Ti interface in group 1 was smaller than the E7-MAO interface fracture in group 3, which demonstrated a stronger adhesion of PLC-MAO than PLC-Ti. In group 2 and group 4, the facture interface between E7-Ti and E7-MAO was similar, which indicated comparable adhesion strength for PLC-MAO and PLC-Ti with antibiotics (white arrows in Figure 5). Figure 6 shows the adhesion strength of the PLC-E7 interface in each group. Comparing group 1 with group 3, the use of MAO coating did increase the average maximum load and adhesion strength of the interface, but the difference was not significant $(p>0.05)$. The addition of antibiotics also noticeably increased the adhesion strength of the interface (group 1 to group 2, and group 3 to group 4) (Figure 6). The increase in adhesion strength from group 1 to group 2 was statistically significant $(p<0.05)$. This demonstrated strong adhesion between the PLC-MAO and PLC-Ti interfaces.
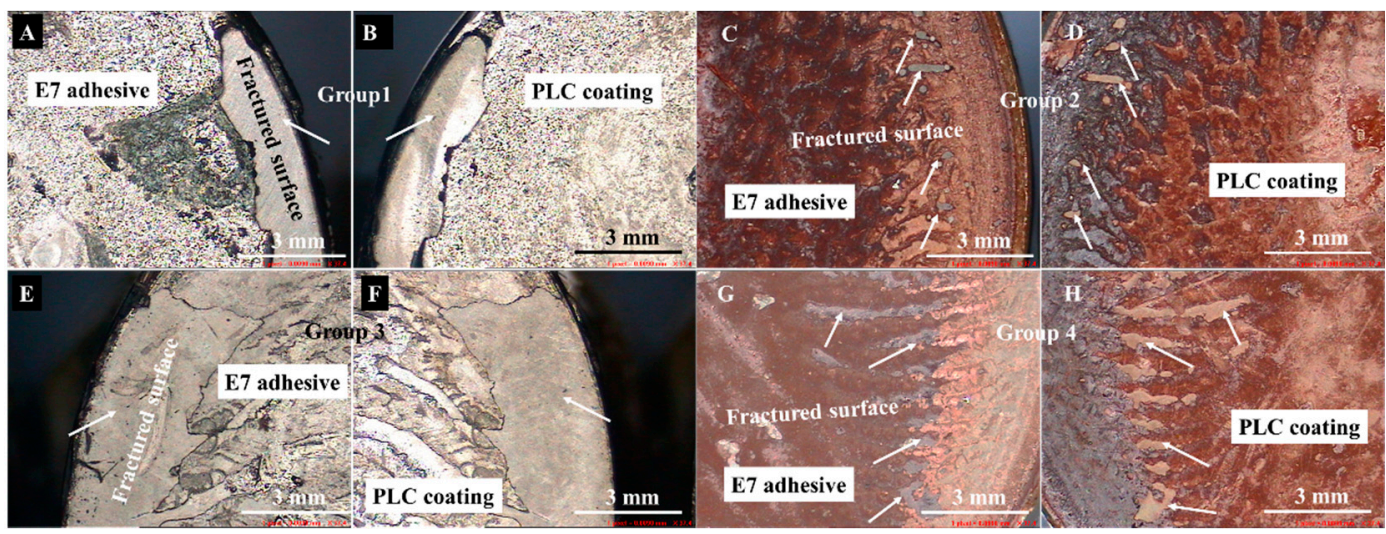

Figure 5. Images of fractured surface for (A,B) PLC coating (group 1), (C,D) PLC coating with antibiotics (group 2), (E,F) double coating (group 3), (G,H) double coating with antibiotics (group 4).

Table 2. The details of which interface failed for each group during tensile testing.

\begin{tabular}{ccccc}
\hline \multirow{2}{*}{$\begin{array}{c}\text { Group } \\
\text { Number }\end{array}$} & Coatings & $\begin{array}{c}\text { Strong Adhesion } \\
\text { Interface }\end{array}$ & \multicolumn{2}{c}{ Failure Mode of Paired Specimens in Each Group } \\
\cline { 3 - 5 } & & Main Facture Interface & $\begin{array}{c}\text { Symmetrical Facture } \\
\text { Interface }\end{array}$ \\
\cline { 3 - 5 } & Test Specimen & between Specimens & Control Specimen \\
\hline 1 & Only PLC coating & Ti-PLC & PLC-E7 & E7-Ti \\
2 & $\begin{array}{c}\text { Only PLC coating } \\
\text { with antibiotics }\end{array}$ & $\begin{array}{c}\text { Ti-PLC with } \\
\text { antibiotics }\end{array}$ & PLC-E7 with antibiotics & E7 with antibiotics-Ti \\
3 & $\begin{array}{c}\text { Double coating } \\
\text { Ti-MAO-PLC }\end{array}$ & PLC-E7 & E7-MAO -Ti \\
4 & $\begin{array}{c}\text { Double coating } \\
\text { with antibiotics }\end{array}$ & $\begin{array}{c}\text { Ti-MAO-PLC with } \\
\text { antibiotics }\end{array}$ & PLC-E7 with antibiotics & E7 with antibiotics -MAO-Ti \\
\hline
\end{tabular}




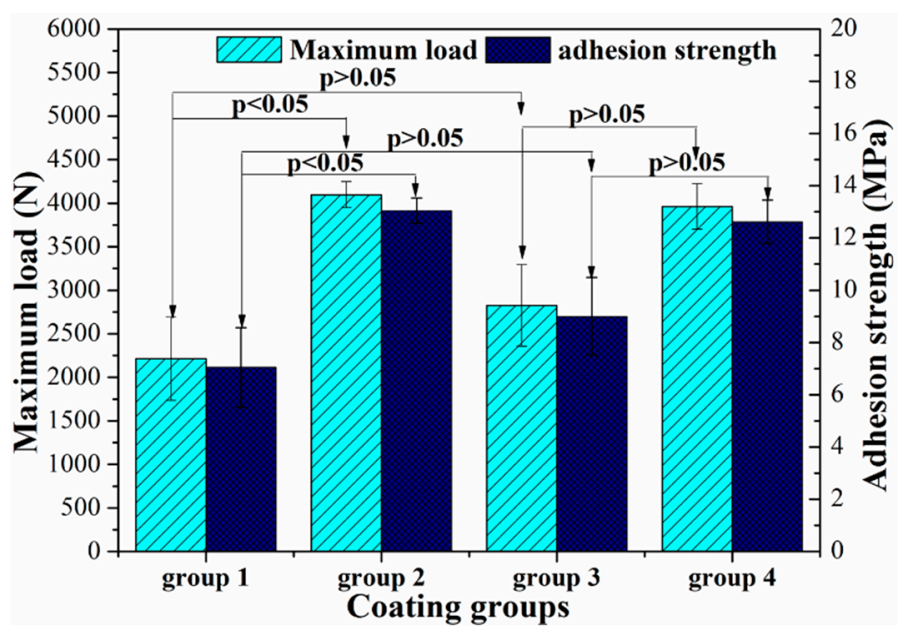

Figure 6. The adhesion strength of PLC-E7 interface in each group.

\subsection{Degradation and Antibiotic Delivery Rate of Resorbable PLC Coating}

Figure 7 shows the mass loss of the PLC coatings with antibiotics over time. The first $24 \mathrm{~h}$ saw a rapid decrease in mass, with $24.28 \%$ of the mass lost through a combination of degradation of the PLC coating and the release of antibiotics. Smaller peaks appeared at 32 and $72 \mathrm{~h}$, and then from $80 \mathrm{~h}$ there was very little change in mass for the remainder of the study.

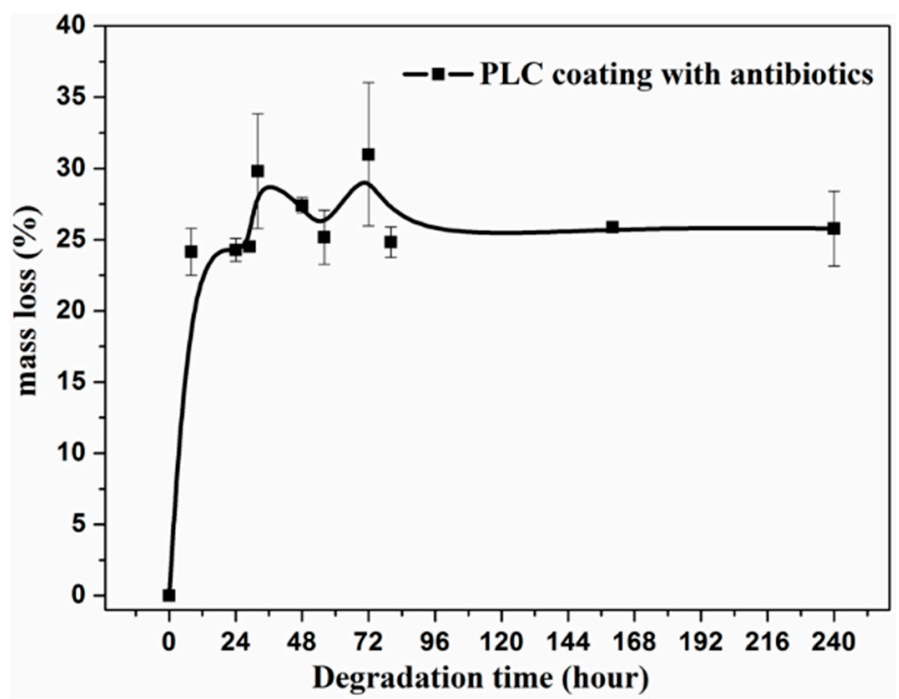

Figure 7. The mass loss of the PLC coatings with antibiotics over time.

As the material degraded, the coatings with antibiotics became highly porous, and the amount and size of the pores increased over time (Figure $8 \mathrm{~A}-\mathrm{H}$ ). The pores also had a nonuniform distribution (Figure 8B-H). At $0 \mathrm{~h}$, the antibiotic particles were dispersed in the surface of the PLC coating or were completely covered by the PLC coating (Figure 8A). 


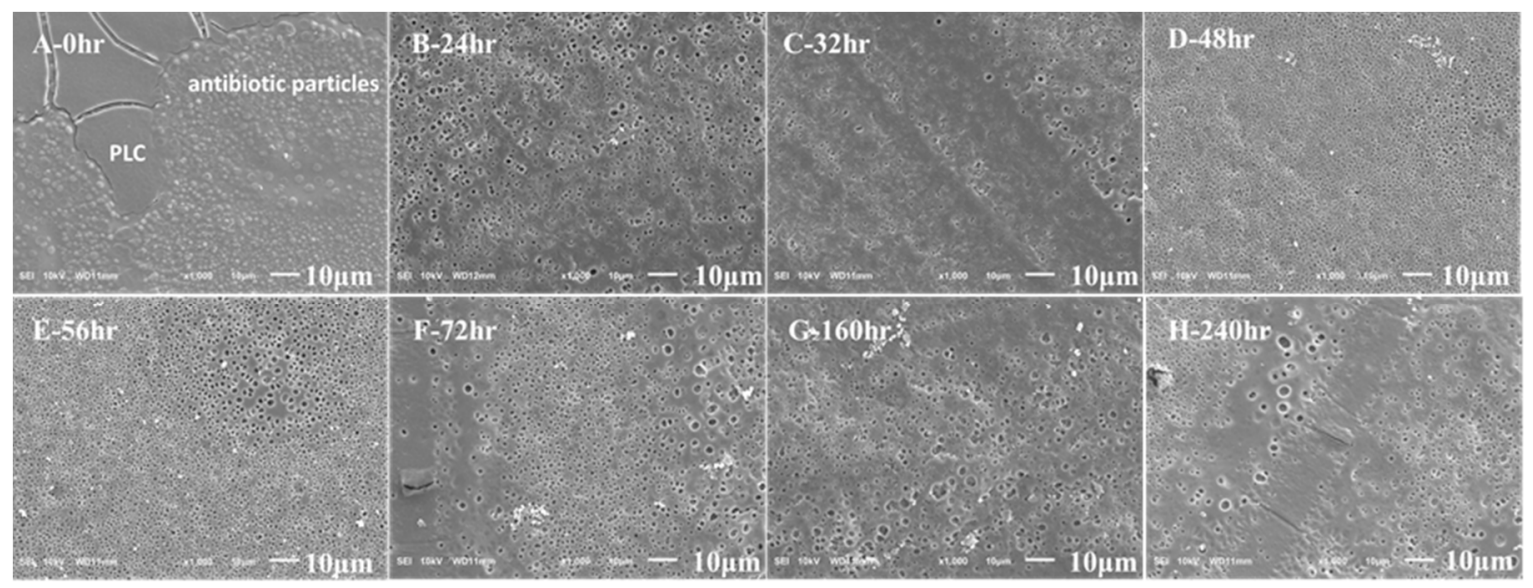

Figure 8. Surface morphology of double coating with antibiotics during degradation time: (A) $0 \mathrm{~h}$; (B) $24 \mathrm{~h}$; (C) $32 \mathrm{~h}$; (D) 48 h; (E) 56 h; (F) 72 h; (G) 160 h; (H) $240 \mathrm{~h}$.

The release rate of antibiotics from the PLC coatings is shown in Figure 9. The linear fitted equations of rifampicin and minocycline hydrochloride are shown in Figure 9A-B. Although the rifampicin and minocycline hydrochloride had a similar trend of release rate, the actual release rate of rifampicin was quicker (Figure $9 \mathrm{C}$ ). The cumulative release of antibiotics rose sharply up to approximately $24 \mathrm{~h}$, after which there were a few smaller peaks up to $80 \mathrm{~h}$. From $80 \mathrm{~h}$ to the end of the study at $240 \mathrm{~h}$, the cumulative release concentration of antibiotics was relatively steady and plateaued over time (Figure 9C). This can be interpreted to mean an almost complete release of antibiotics from the coating. At $72 \mathrm{~h}$, the cumulative release of antibiotics reached over $70 \%$ of the final end release amount at $240 \mathrm{~h}$ (Figure 9C).
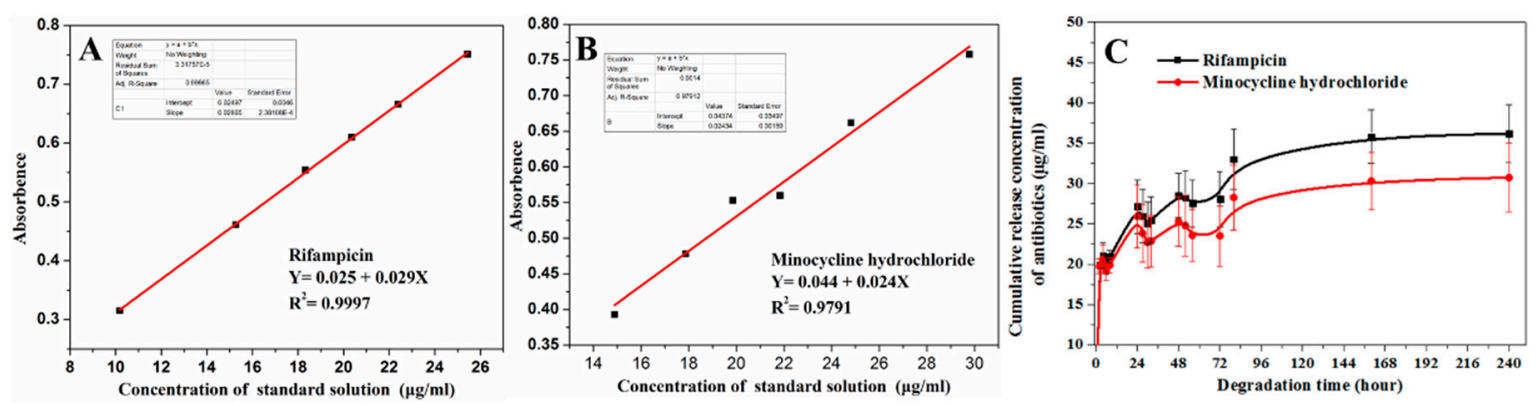

Figure 9. Standard curves of (A) rifampicin and (B) minocycline hydrochloride; (C) cumulative release concentration of antibiotics during degradation time.

\section{Discussion}

\subsection{Interaction between $M A O$ and PLC Coatings}

A key finding of this work is that the combination of an MAO coating and PLC coating with antibiotics increased the adhesion strength of the coatings (Figures 5 and 6). The fracture mode at the PLC-E7 interface in each group demonstrated the strong adhesion of the PLC-MAO interface in specimens with double coating (Figure 5). The fracture surface observed at the E7-Ti interface in group 1 was smaller than the E7-MAO interface fracture in group 3, which demonstrated a stronger adhesion of PLC-MAO than PLC-Ti (Figure 5). The adhesive strength was found to be influenced by the concentration of the PLC solution, the surface structure of the titanium substrate, and the composition of the coatings. Different concentrations of PLC solution affected the surface morphology and thickness of the PLC coating (Figure 4). The most suitable thickness of PLC coating was identified to be $5.4 \pm 0.2 \mu \mathrm{m}$ with a PLC solution concentration of $5 \mathrm{wt} \%$ (Figure $4 \mathrm{D}, \mathrm{L}$ ). In this condition, the porous structure of the MAO coating was mostly filled by the PLC, but a few pores remained and gave 
the implant a rough surface. The rough surface of implant with double coatings could help to stabilize the implant in the immediate post-operative period [10]. The porous MAO coating also permitted the PLC solution to integrate with the coating and increase the adhesive strength (Figures 4 and 6). The protrusions at the MAO-PLC interface (Figure $4 \mathrm{H}-\mathrm{J}$ ), which were caused by the PLC filling the porous structure of the MAO coating, increased the mechanical strength of the coating [23]. The addition of antibiotics to the PLC coating also acted to increase the adhesive strength of PLC-E7 (Figure 6). The increase in adhesion strength from group 1 to group 2 was statistically significant $(p<0.05)$. The stronger adhesion is likely due to the physical forces between chemical groups [23]. The antibiotics also changed the surface morphology of the PLC coating (Figure 8A), with the antibiotics located both on the surface of the coating and embedded within the body of the coating. The rougher surface, as opposed to the smooth surface of the PLC-only coating (Figure 4D), may affect the adhesion strength of the E7-PLC interface. However, the mechanism behind the increased adhesion strength of coatings containing antibiotics needs further investigation.

\subsection{Degradation and Antibiotic Release Rate of Double Coatings}

The PLC-only coating had a slow degradation rate (Figure 7) due to its material composition. PLC is a copolymer of poly-L-lactide (PLLA) and poly- $\varepsilon$-carproactone (PCL), and typically PLLA and PCL have a 3-7 year degradation cycle [18]. The initial sharp decrease in mass was mainly due to the burst release of antibiotics (Figure 8A-B and Figure 9C). The smaller peaks of mass loss at 32 and $72 \mathrm{~h}$ may be caused by the accumulative release of antibiotics and slight changes in the mass of the coatings (Figures 8 and 9C). Even with the degradation of the PLC coatings, the uncovered porous structure of the MAO coating may still promote implant stability, as well as being anticorrosive [24] and biocompatible $[25,26]$.

Early infection typically occurs within less than 2 weeks post-implantation, and is often caused by infectious agents introduced during trauma or the surgical procedure itself, leading to highly pathogenic microbial infections (Staphylococcus aureus, gram-negative bacilli) [2]. The antibiotic release cycle of the PLC coating was approximately 10 days (Figure 9C), which would be sufficient to tackle early infections. Cheng et al. [23,27] reported a sustained degradation time of 4-8 h for MAO-chitosan composite coatings embedded with cefazolin sodium. Such rapid degradation could not be reasonably expected to treat early infections due to the early release and subsequent metabolism. In this current study, the burst release of antibiotics in the first $24 \mathrm{~h}$ was due to the diffusion of antibiotics located on the surface of the coating. This early release could help to reduce the risk of developing an infection post-implantation by eliminating any bacteria surrounding the device before it could adhere to the implant and form a biofilm which antibiotics could not easily penetrate [19]. Following this initial burst, the subsequent sustained release of antibiotics over time due to the slow degradation rate of PLC could help to prevent bacterial infections as the wound heals. The release rates of rifampicin and minocycline hydrochloride were different due to the interaction between chemical groups and the structure of the antibiotics and PLC $[23,27]$. The linear structure of minocycline hydrochloride can merge better with the linear PLC and thus has a slower rate of release (Figure 9C).

The aim of this study was to examine the mechanical properties of a novel double-coating and present a suitable release rate for antibiotics that is closely matched to the timing of early infections that often arise post-implantation. As such, this study did not consider the effectiveness of the antimicrobial properties of the new double coating. However, the antibiotics used, rifampicin and minocycline, are wide-spectrum antibiotics commonly used to treat early infections [28-32]. Future studies may consider using an animal model or suitable in vitro test method to evaluate the true antimicrobial effectiveness. Secondly, this study did not consider the impact of sterilisation. The high temperatures associated with steam sterilization and the high-energy of gamma irradiation may accelerate the degradation of the PLC coating and reduce the efficacy of the drugs embedded in the coating [33]. As such, the preferred sterilization method for the device in this study is ethylene oxide [34]. However, antibiotic 
coatings being applied to sterilized metal implants can also be prepared under aseptic conditions in laminar air-flow $[5,12,17,35]$ to ensure the activity of the antibiotics is maintained.

A limitation to the coating methods used in this study is that the dip coating process was controlled by immersion time, but the rate of removal of the implants from the solution could also affect the uniformity of the PLC coating. However, the increased immersion time for dip coating did improve the uniformity of the PLC coating [21].

\section{Conclusions}

This study demonstrated the adhesive properties of a new double-coating of MAO and resorbable poly-L-lactide-co- $\varepsilon$-caproactone (PLC) on Ti-6Al-4V samples. The MAO coating and the addition of antibiotics increased the adhesive strength of the coating. The adhesive strength was affected by the concentration of PLC solution, the surface structure of the titanium substrate, and the composition of the coatings. The antibiotics blended into the PLC coating had a release cycle of approximately 10 days, which would be long enough to reduce the risk of developing an infection after implantation.

Author Contributions: Conceptualization, C.-K.C.; Methodology, X.-Y.C., N.T., X.D.; Validation, C.-K.C.; Formal Analysis, X.-Y.C; Investigation, X.-Y.C.; Data Curation, X.-Y.C.; Writing-Original Draft Preparation, X.-Y.C.; Writing-Review and Editing, C.-K.C.; All authors read and approved the final manuscript.

Funding: This research was funded by the Chinese National Science and Technology Program (National Key Research and Development Plan) (Grant number: 210YBXM2016110002).

Acknowledgments: The authors would like to thank Mr. Colin Mc Clean for his assistance with proofreading this manuscript.

Conflicts of Interest: The authors declare no conflicts of interest.

\section{References}

1. He, X.; Zhang, X.; Wang, X.; Qin, L. Review of antibacterial activity of titanium-based implants' surfaces fabricated by micro-arc oxidation. Coatings 2017, 7, 45. [CrossRef]

2. Schmidmaier, G.; Lucke, M.; Wildemann, B.; Haas, N.P.; Raschke, M. Prophylaxis and treatment of implant-related infections by antibiotic-coated implants: A review. Injury 2006, 37, S105-S112. [CrossRef]

3. Cometa, S.; Bonifacio, M.A.; Baruzzi, F.; de Candia, S.; Giangregorio, M.M.; Giannossa, L.C.; Dicarlo, M.; Mattioli-Belmonte, M.; Sabbatini, L.; De Giglio, E. Silver-loaded chitosan coating as an integrated approach to face titanium implant-associated infections: Analytical characterization and biological activity. Anal. Bioanal. Chem. 2017, 409, 7211-7221. [CrossRef]

4. Young, S.; Lie, S.A.; Hallan, G.; Zirkle, L.G.; Engesaeter, L.B.; Havelin, L.I. Low infection rates after 34,361 intramedullary nail operations in 55 low- and middle-income countries: Validation of the surgical implant generation network (sign) online surgical database. Acta Orthop. 2011, 82, 737-743. [CrossRef]

5. Gollwitzer, H. Antibacterial poly(D,L-lactic acid) coating of medical implants using a biodegradable drug delivery technology. J. Antimicrob. Chemother. 2003, 51, 585-591. [CrossRef] [PubMed]

6. Jennings, J.A.; Beenken, K.E.; Skinner, R.A.; Meeker, D.G.; Smeltzer, M.S.; Haggard, W.O.; Troxel, K.S. Antibiotic-loaded phosphatidylcholine inhibits staphylococcal bone infection. World J. Orthop. 2016, 7, 467-474. [CrossRef] [PubMed]

7. Malizos, K.; Blauth, M.; Danita, A.; Capuano, N.; Mezzoprete, R.; Logoluso, N.; Drago, L.; Romano, C.L. Fast-resorbable antibiotic-loaded hydrogel coating to reduce post-surgical infection after internal osteosynthesis: A multicenter randomized controlled trial. J. Orthop. Traumatol. Off. J. Ital. Soc. Orthop. Traumatol. 2017, 18, 159-169. [CrossRef]

8. Jennings, J.A.; Carpenter, D.P.; Troxel, K.S.; Beenken, K.E.; Smeltzer, M.S.; Courtney, H.S.; Haggard, W.O. Novel antibiotic-loaded point-of-care implant coating inhibits biofilm. Clin. Orthop. Relat. Res. 2015, 473, 2270-2282. [CrossRef] [PubMed]

9. Peltonen, L.I.; Kinnari, T.J.; Aarnisalo, A.A.; Kuusela, P.; Jero, J. Comparison of bacterial adherence to polylactides, silicone, and titanium. Acta Oto-Laryngol. 2009, 127, 587-593. [CrossRef] 
10. Gimeno, M.; Pinczowski, P.; Mendoza, G.; Asin, J.; Vazquez, F.J.; Vispe, E.; Garcia-Alvarez, F.; Perez, M.; Santamaria, J.; Arruebo, M.; et al. Antibiotic-eluting orthopedic device to prevent early implant associated infections: Efficacy, biocompatibility and biodistribution studies in an ovine model. J. Biomed. Mater. Research. Part Bapplied Biomater. 2018, 106, 1976-1986. [CrossRef] [PubMed]

11. Gimeno, M.; Pinczowski, P.; Vazquez, F.J.; Perez, M.; Santamaria, J.; Arruebo, M.; Lujan, L. Porous orthopedic steel implant as an antibiotic eluting device: Prevention of post-surgical infection on an ovine model. Int. J. Pharm. 2013, 452, 166-172. [CrossRef] [PubMed]

12. Gnedenkov, S.V.; Sharkeev, Y.P.; Sinebryukhov, S.L.; Khrisanfova, O.A.; Legostaeva, E.V.; Zavidnaya, A.G.; Puz', A.V.; Khlusov, I.A.; Opra, D.P. Functional coatings formed on the titanium and magnesium alloys as implant materials by plasma electrolytic oxidation technology: Fundamental principles and synthesis conditions. Corros. Rev. 2016, 34, 65-83. [CrossRef]

13. Cerchier, P.; Pezzato, L.; Brunelli, K.; Dolcet, P.; Bartolozzi, A.; Bertani, R.; Dabala, M. Antibacterial effect of peo coating with silver on AA7075. Mater. Sci. Eng. C 2017, 75, 554-564. [CrossRef]

14. Mohedano, M.; Luthringer, B.J.C.; Mingo, B.; Feyerabend, F.; Arrabal, R.; Sanchez-Egido, P.J.; Blawert, C.; Willumeit-Römer, R.; Zheludkevich, M.L.; Matykina, E. Bioactive plasma electrolytic oxidation coatings on Mg-Ca alloy to control degradation behaviour. Surf. Coat. Technol. 2017, 315, 454-467. [CrossRef]

15. Durdu, S. Characterization, bioactivity and antibacterial properties of copper-based $\mathrm{TiO}_{2}$ bioceramic coatings fabricated on titanium. Coatings 2018, 9, 1. [CrossRef]

16. Pezzato, L.; Cerchier, P.; Brunelli, K.; Bartolozzi, A.; Bertani, R.; Dabalà, M. Plasma electrolytic oxidation coatings with fungicidal properties. Surf. Eng. 2018, 35, 325-333. [CrossRef]

17. Vester, H.; Wildemann, B.; Schmidmaier, G.; Stockle, U.; Lucke, M. Gentamycin delivered from a pdlla coating of metallic implants: In vivo and in vitro characterisation for local prophylaxis of implant-related osteomyelitis. Injury 2010, 41, 1053-1059. [CrossRef] [PubMed]

18. Ginjupalli, K.; Shavi, G.V.; Averineni, R.K.; Bhat, M.; Udupa, N.; Nagaraja Upadhya, P. Poly( $\alpha$-hydroxy acid) based polymers: A review on material and degradation aspects. Polym. Degrad. Stab. 2017, 144, 520-535. [CrossRef]

19. Zilberman, M.; Elsner, J. Antibiotic-eluting medical devices for various applications. J. Control. Release 2008, 130, 202-215. [CrossRef] [PubMed]

20. ter Boo, G.J.; Grijpma, D.W.; Moriarty, T.F.; Richards, R.G.; Eglin, D. Antimicrobial delivery systems for local infection prophylaxis in orthopedic- and trauma surgery. Biomaterials 2015, 52, 113-125. [CrossRef]

21. Torabi, A.; Etsell, T.H.; Sarkar, P. Dip coating fabrication process for micro-tubular sofcs. Solid State Ion. 2011, 192, 372-375. [CrossRef]

22. ISO 4624-Paints Varnishes and Plastics-Pull-off Test for Adhesion; ISO Technical Committees: Geneva, Switzerland, 2003.

23. Cheng, S.; Wei, D.; Zhou, Y. Mechanical and corrosion resistance of hydrophilic sphene/titania composite coatings on titanium and deposition and release of cefazolin sodium/chitosan films. Appl. Surf. Sci. 2011, 257, 2657-2664. [CrossRef]

24. Khanna, R.; Ong, J.; Oral, E.; Narayan, R. Progress in wear resistant materials for total hip arthroplasty. Coatings 2017, 7, 99. [CrossRef]

25. Zhao, Q.-M.; Cheng, L.; Liu, Z.-T.; Zhao, J.-J. Surface characteristics of Zinc- $\mathrm{TiO}_{2}$ coatings prepared via micro-arc oxidation. Compos. Interfaces 2014, 21, 585-593. [CrossRef]

26. Li, G.; Cao, H.; Zhang, W.; Ding, X.; Yang, G.; Qiao, Y.; Liu, X.; Jiang, X. Enhanced osseointegration of hierarchical micro/nanotopographic titanium fabricated by microarc oxidation and electrochemical treatment. Acs Appl. Mater. Interfaces 2016, 8, 3840-3852. [CrossRef]

27. Cheng, S.; Wei, D.; Zhou, Y. Structure of microarc oxidized coatings containing Si, Ca and Na on titanium and deposition of cefazolin sodium/chitosan composite film. Surf. Coat. Technol. 2011, 205, 3798-3804. [CrossRef]

28. Clmneck, N.; Marcelis, L.; Amiri-Lamraski, M.H.; Gordts, B. Treatment of severe staphylococcal infections with treatment of severe staphylococcal infections with. J. Antimicrob. Chemother. 1984, 13, 17-22. [CrossRef]

29. Goto, Y.; Hiramatsu, K.; Nasu, M. Improved efficacy with nonsimultaneous administration of netilmicin and minocycline against methicillin-resistant staphylococcus aureus in in vitro and in vivo models. Int. J. Antimicrob. Agents 1999, 39-46. [CrossRef] 
30. Kadurugamuwa, J.L.; Sin, L.V.; Yu, J.; Francis, K.P.; Purchio, T.F.; Contag, P.R. Noninvasive optical imaging method to evaluate postantibiotic effects on biofilm infection in vivo. Antimicrob. Agents Chemother. 2004, 48, 2283-2287. [CrossRef]

31. Gomez, E.O.; Jafary, A.; Dever, L.L. Daptomycin and rifampin for the treatment of methicillin-resistant staphylococcus aureus septic pulmonary emboli in the absence of endocarditis. Microb. Drug Resist. 2010, 16, 241-244. [CrossRef]

32. Kastoris, A.C.; Rafailidis, P.I.; Vouloumanou, E.K.; Gkegkes, I.D.; Falagas, M.E. Synergy of fosfomycin with other antibiotics for gram-positive and gram-negative bacteria. Eur. J. Clin. Pharmacol. 2010, 66, 359-368. [CrossRef]

33. Tipnis, N.P.; Burgess, D.J. Sterilization of implantable polymer-based medical devices: A review. Int. J. Pharm. 2018, 544, 455-460. [CrossRef]

34. Mendes, G.C.C.; Brandão, T.R.S.; Silva, C.L.M. Ethylene oxide sterilization of medical devices: A review. Am. J. Infect. Control 2007, 35, 574-581. [CrossRef]

35. Schmidmaier, G.; Wildemann, B.; Stemberger, A.; Haas, N.P.; Raschke, M. Biodegradable poly(D,L-lactide) coating of implants for continuous release of growth factors. J. Biomed. Mater. Res. Appl. Biomater. 2001, 449-455. [CrossRef]

(C) 2019 by the authors. Licensee MDPI, Basel, Switzerland. This article is an open access article distributed under the terms and conditions of the Creative Commons Attribution (CC BY) license (http://creativecommons.org/licenses/by/4.0/). 